\title{
Lovastatin production by Aspergillus terreus in solid state and submerged fermentations
}

\author{
T.G. Gulyamova, D.M. Ruzieva, S.M. Nasmetova, R.S. Sattarova*, K.V. Lobanova, \\ L.A. Abdulmyanova, G.A. Rasulova \\ Department of Biochemistry of Physiologically Active Compounds, Institute of Microbiology of the Academy of Sciences RU, UZBEKISTAN \\ *Corresponding Author: e-mail: regina.s.sattarova@gmail.com, Tel. +998-90-1898179, Fax +998-71-2442582
}

\begin{abstract}
Lovastatin production by Aspergillus terreus indigenous strains in submerged (SmF) and solid state fermentations (SSF) have been studied. To evaluate the ability to produce lovastatin various cultivation media and substrates have been used. The obtained data showed good lovastatin yield by A. terreus 4 and A. terreus 20 both in SmF and SSF. At submerged cultivation of $A$. terreus 4 and $A$. terreus 20 on five different glucose and lactose based media the highest titer of lovastatin has been obtained on lactose based media, namely $276 \mathrm{mg} / \mathrm{l}$ and $236 \mathrm{mg} / \mathrm{l}$, respectively. Five various types of bran have been tested as solid substrates for production of lovastatin in SSF - wheat bran, oat bran, maize bran, rice bran and mix of wheat and peanut bran. It has been observed that fermentation of A. terreus 4 on wheat and A. terreus 20 on oat bran causes the highest lovastatin yield - 9.7 and $9.56 \mathrm{mg} / \mathrm{g}$, respectively.
\end{abstract}

Keywords: lovastatin, submerged fermentation, solid state fermentation, production

DOI: http://dx.doi.org/10.4314/ijest.v5i3.2

\section{Introduction}

Lovastatin is a fungal secondary metabolite used for lowering blood cholesterol. It acts as an effective inhibitor of the enzyme hydroxymethylglutaryl coenzyme A (HMG-CoA) reductase (mevalonate: NADP1 oxydoreductase, EC 1.1.1.34) that catalyzes the reduction of HMG-CoA to mevalonate during synthesis of cholesterol (Alberts et al., 1980). It has been shown that lovastatin very competitively inhibits the reductase which decrease serum cholesterol levels by blocking cholesterol biosynthesis.

Lovastatin has a polyketide structure and is produced as a secondary metabolite by a variety of filamentous fungi such as Monascus (M. ruber, M. purpureus, M. pilosus, M. anka), Penicillium (P. citrinum), Paecilomyces viridis, and Aspergillus (A. terreus) (Manzoni et al., 2002).

Commercial production of lovastatin is conventionally performed by liquid SmF using A. terreus mutants (Barrios-Gonzales et al., 2010). To date, there are many publications focused on studies of cultivation regimes for producing statins (Bizukojc et al., 2009). In the last years, SSF is becoming an alternative to SmF for generating many fungal products including statins. Comparative studies have shown that solid-state fermentation has advantages over SmF such as higher and faster yield, and less water need in up-stream processing which minimizes production expense (Holker et al., 2004).

In the present work, production of lovastatin in conventional SmF and in SSF on natural solid substrates has been studied comparatively using two domestic isolates of Aspergillus terreus selected from 30 strains which were isolated from saline soils and maintained in Culture Collection of the Institute of Microbiology of the Academy of Sciences of the Republic of Uzbekistan. 


\section{Materials and Methods}

2.1 Microorganisms and inoculum preparation: A. terreus strains were isolated from soils of the Navoi region, Uzbekistan. Isolates were grown on Czapek-Dox agar slants at $28^{\circ} \mathrm{C}$ until complete sporulation. Conidiospores were harvested from slants with $5 \mathrm{ml}$ of sterile solution of $0,85 \% \mathrm{NaCl}, 0,2 \%$ Tween 80 and transferred into $250 \mathrm{ml}$ Erlenmeyer flasks containing $50 \mathrm{ml}$ medium (g/l): $10 \mathrm{~g}$ glucose, $10 \mathrm{~g}$ oat meal, $10 \mathrm{~g}$ corn steep liquor, $0,2 \mathrm{~g}$ polyethylene glycol, and $10 \mathrm{ml}$ of trace elements $-100 \mathrm{mg}$ $\mathrm{Na}_{2} \mathrm{~B}_{4} \mathrm{O}_{7} \cdot 10 \mathrm{H}_{2} \mathrm{O}, 50 \mathrm{mg} \mathrm{MnCl}, 50 \mathrm{mg} \mathrm{Na} \mathrm{MoO}_{4} \cdot 5 \mathrm{H}_{2} \mathrm{O}$, and $250 \mathrm{mg} \mathrm{CuSO} \cdot 5 \mathrm{H}_{2} \mathrm{O}$ - per liter of solution (Kumar et al., 2000). The flask with medium was inoculated with $3 \times 10^{7}$ conidiospores, held on rotary shaker at $160 \mathrm{rpm}$ for 2 days at $28-30^{\circ} \mathrm{C}$ and then was used as inoculum.

2.2 Liquid submerged fermentation: Different glucose and lactose based lovastatin production media were used for SmF. $10 \mathrm{ml}$ of conidiospores were inoculated in $300 \mathrm{ml}$ Erlenmeyer flasks, containing $100 \mathrm{ml}$ of the following media $(\mathrm{g} / \mathrm{l})$ :

\#1: Glucose - 10, corn steep liquor - 5, tomato paste - 40, oatmeal - 10, pH 6, (Monaghan et al., 1980).

\#2: Glucose - 30, glycerol - 70, peptone - 8, soybean meal - 30, pH 6,4 (Manzoni et al., 1998).

\#3: Glucose - 45, Na glutamate - 12,5, $\mathrm{KH}_{2} \mathrm{PO}_{4}-5, \mathrm{~K}_{2} \mathrm{HPO}_{4}-5, \mathrm{FeSO}_{4} \cdot 7 \mathrm{H}_{2} \mathrm{O}, \mathrm{MnSO}_{4} \cdot 4 \mathrm{H} 2 \mathrm{O}-0,1, \mathrm{ZnSO}_{4} \cdot 7 \mathrm{H}_{2} \mathrm{O}$ $-0,2, \mathrm{MgSO}_{4} \cdot 7 \mathrm{H}_{2} \mathrm{O}-0,1$, trace elements $-1 \mathrm{ml}, \mathrm{pH} 6,5$ (Hajjaj et al., 2001).

\#4: Lactose - 20, yeast extract $-8, \mathrm{KH}_{2} \mathrm{PO}_{4}-1,51, \mathrm{MgSO}_{4} \cdot 7 \mathrm{H} 2 \mathrm{O}-1,51, \mathrm{NaCl}-0,4, \mathrm{ZnSO}_{4} \cdot 7 \mathrm{H}_{2} \mathrm{O}-1, \mathrm{Fe}\left(\mathrm{NO}_{3}\right)$ $.9 \mathrm{H}_{2} \mathrm{O}-2$, biotin $-0,04 \mathrm{M \Gamma}$, trace elements $-1 \mathrm{ml}, \mathrm{pH} 6,0$ (Casas Lopez et al, 2003).

\#5: Lactose - 70, yeast extract -8 , defatted soybean meal - 0,5, polyethylene glycol $2000-0,5, \mathrm{KCl}-1, \mathrm{~K}_{2} \mathrm{HPO}_{4}-1$, pH 6,5 (Lai et al, 2005).

Fermentation was carried out at $28^{\circ} \mathrm{C}$ in flasks held on a rotary platform shaker at $160 \mathrm{rpm}$ for 24 days. Lovastatin was extracted only from biomass after centrifugation of whole cultural suspension at $6000 \mathrm{rpm}$ for $20 \mathrm{~min}$. $1 \mathrm{~g}$ of mycelium was washed with $0,05 \mathrm{M} \mathrm{HCl}$ and extracted with $20 \mathrm{ml}$ of acetonitrile in a rotary shaker at $160 \mathrm{rpm}$ for $60 \mathrm{~min}$. Extracts were dried with $\mathrm{Na}_{2} \mathrm{SO}_{4}$, concentrated to $2 \mathrm{ml}$ by vacuum evaporation and used for lovastatin estimation.

2.3 Solid state fermentation: Substrates such as wheat bran, oat bran, rice bran, maize bran and mix of wheat and peanut bran were used in the solid state fermentation process. Before fermentation, substrates were ground to the size of 20 mesh. SSF was performed in $500 \mathrm{ml}$ conical flasks, containing $50 \mathrm{~g}$ of solid substrate. The flasks were autoclaved for $40 \mathrm{~min}$ at $121^{\circ} \mathrm{C}$, the substrate's moisture content was measured and adjusted to a level 55-65\% with nutrient solution (\%): glucose - 11, glycerol -16, $\mathrm{MgSO}_{4}-0,75,\left(\mathrm{NH}_{4}\right)_{2} \mathrm{HSO}_{4}-2,3, \mathrm{KH}_{2} \mathrm{PO}_{4}-2$, maltose - 5, $\mathrm{pH}-7,5$. After moistening of substrate, $2,5 \mathrm{ml}$ of inoculum (with spore concentration of $10^{7}-10^{8} \mathrm{ml}^{-1}$ ) was added. The flasks were shaken evenly and incubated at $28^{\circ} \mathrm{C}$ for 14 days. At the end of incubation SSF substrate was dried at $100-105^{\circ} \mathrm{C}$, ground using a porcelaine pestle and mortar to a fine powder and used to estimate the lovastatin content by HPLC analysis (Morovjan et al., 1997).

2.4 Lovastatin extraction: After SmF, lovastatin was extracted from biomass after centrifugation of the whole culture suspension at $6000 \mathrm{rpm}$ for $20 \mathrm{~min}$. $1 \mathrm{~g}$ of mycelium was washed using $0,05 \mathrm{M} \mathrm{HCL}$ and extracted with $20 \mathrm{ml}$ of acetonitrile on rotary shaker for $60 \mathrm{~min}$ at $160 \mathrm{rpm}$. Extracts were dried with $\mathrm{Na}_{2} \mathrm{SO}_{4}$, concentrated to $2 \mathrm{ml}$ by vacuum evaporation and used for lovastatin estimation. After SSF, lovastatin was extracted from $1 \mathrm{~g}$ of ground substrate using $20 \mathrm{ml}$ of acetonitrile by shaking on a rotary shaker for $60 \mathrm{~min}$ at $160 \mathrm{rpm}$, centrifuged for $10 \mathrm{~min}$ at $6000 \mathrm{rpm}$, and then the supernatant was used for HPLC analysis.

2.5 HPLC analysis of lovastatin: Prepared extract samples, obtained both by SmF and SSF were quantitatively analyzed for the presence of lovastatin. HPLC analysis was carried out in a reverse phase Zorbax Eclipse XDB C-18 (150x4,6 мm i.d., $5 \mu \mathrm{m})$ column. The mobile phase consisted of acetonitrile and water (60:40 by volume) containing $0,1 \%$ phosphoric acid. The sample injection volume was $20 \mu \mathrm{l}$, the eluent flow rate $1,5 \mathrm{ml} / \mathrm{min}$ and the detection wavelength $238 \mathrm{~nm}$. The identity of the compound was confirmed with a commercial sample of lovastatin (Gedeon Richter) as standart (Manzoni et al., 1998).

\section{Results and Discussion}

In our work a two strains A. terreus 4 and A. terreus 20 were analyzed for their potential in lovastatin production using SmF and SSF. Because lovastatin is an intracellular product and mostly accumulated in mycelium, for lovastatin extraction we used mycelial biomass separated from cultural broth. According to Manzoni et al, 83\% of total lovastatin has been extracted from separated mycelium of A. terreus, only $17 \%$ from cultural filtrate, $60 \%$ of total lovastatin loss at direct extraction of the whole culture (Manzoni et al., 1998).

For liquid SmF we applied different lactose- and glucose-based media. Carbon and nitrogen sources are directly linked with the formation of biomass and metabolites, therefore these nutrients generally play a dominant role in fermentation productivity among the major culture nutrients (Barrios-Gonzales et al., 2010; Bizukojc et al., 2009). Secondary metabolism can be 
regulated both by nature and concentration of the carbon source, such as catabolic repression by glucose.

Biosynthesis of lovastatin as secondary metabolite also has been found to depend on the carbon sources. According to many authors, a slowly utilizable carbon source is preferable for high lovastatin production. For example, Casas Lopes et al. testing fructose, lactose and glycerol, showed that the most slowly utilizable carbon source is lactose, and it caused the highest level of biosynthesis of lovastatin by A. terreus (Casas Lopes et al., 2003). Hajjaj et al. investigating the biosynthesis of lovastatin by A. terreus ATCC74135 have found that the use of a glucose and lactose mixture leads to a good lovastatin yield (Hajjaj et al., 2001). Lai et al. studied the biosynthesis of lovastatin and itaconic acid by A. terreus ATCC20542 and observed that lovastatin yield was almost 10 times higher on medium containing lactose than on medium containing glucose (Lai et al., 2007). Szakacz et al. also showed that the maximum lovastatin production by the Hungarian strain A. terreus TUB F-514 was observed with the use of lactose as the carbon source and the lovastatin titer was $400 \mathrm{mg} / \mathrm{l}$, while the lovastatin titer on sucrose was $40 \%$ less than on lactose (Szakacz et al., 1998).

We used five different glucose- and lactose-based media. Lovastatin concentrations were estimated throughout 24 days of cultures growth. It was observed that product accumulation dependents from used media and takes place at 10-22 ${ }^{\text {th }}$ day of growth. Results of SmF of A. terreus 4 and A. terreus 20 on glucose- and lactose-based media are presented in Table 1. As shown, in both $A$. terreus strains lovastatin yield was higher in lactose-based media. It should be mentioned that their productivity is comparable with lovastatin yield in shake flask fermentation of A. terreus ATCC 20542 and A. terreus ATCC74135 (Bizukojc et al., 2009). Data on $\mathrm{SmF}$ of A. terreus 4 and A. terreus 20 confirm that media with a slowly utilizable carbon source are preferential for lovastatin production.

Table 1. Effect of carbon and nitrogen sources on lovastatin yield by Aspergillus terreus using submerged cultivation ${ }^{\text {a) }}$

\begin{tabular}{|c|c|c|c|c|c|}
\hline \# & $\begin{array}{c}\text { Carbon source } \\
(\mathrm{g} / \mathrm{l})\end{array}$ & $\underset{(\mathrm{g} / \mathrm{l})}{\operatorname{Nitrogen} \text { source }}$ & $\underset{(\mathrm{mg} / \mathrm{l})}{\operatorname{Lovastatin} \text { titer }}$ & $\begin{array}{l}\text { Time } \\
\text { (days) }\end{array}$ & Strain \\
\hline \multirow{2}{*}{1} & \multirow{2}{*}{ Glu (10) } & \multirow{2}{*}{$\begin{array}{l}\text { CSL (5) } \\
\text { TP (40) } \\
\text { OM (10) }\end{array}$} & 112 & $10^{\text {th }}$ & A.terreus 4 \\
\hline & & & 121 & $14^{\text {th }}$ & A.terreus 20 \\
\hline \multirow[t]{2}{*}{2} & \multirow{2}{*}{$\begin{array}{l}\text { Glu (30) } \\
\text { Gly (70) }\end{array}$} & \multirow{2}{*}{$\begin{array}{l}\text { SM (30) } \\
\text { PE (8) }\end{array}$} & 61 & $16^{\text {th }}$ & A.terreus 4 \\
\hline & & & 51 & $12^{\text {th }}$ & A.terreus 20 \\
\hline \multirow[t]{2}{*}{3} & \multirow[t]{2}{*}{ Glu (45) } & \multirow[t]{2}{*}{ Na-Glu $(12,5)$} & 137,6 & $10^{\text {th }}$ & A.terreus 4 \\
\hline & & & 29,8 & $14^{\text {th }}$ & A.terreus 20 \\
\hline \multirow[t]{2}{*}{4} & \multirow[t]{2}{*}{ Lac (20) } & \multirow[t]{2}{*}{ YE (8) } & 136 & $20^{\text {th }}$ & A.terreus 4 \\
\hline & & & 236 & $14^{\text {th }}$ & A.terreus 20 \\
\hline \multirow{2}{*}{5} & \multirow[t]{2}{*}{ Lac $(70 \mathrm{~g} / 1)$} & \multirow{2}{*}{$\begin{array}{c}\text { YE }(8) \\
\operatorname{DSM}(0,5)\end{array}$} & 276 & $22^{\text {th }}$ & A.terreus 4 \\
\hline & & & 214 & $20^{\text {th }}$ & A.terreus 20 \\
\hline
\end{tabular}

a) Glu, glucose; Gly, glycerol; Lac, lactose; CSL, corn steep liquor; TP, tomato paste; OM, oat meal; DSM, defatted soybean meal; Na-Glu, Na glutamate; YE, yeast extract; SM, soybean meal; PE, peptone.

During our evaluation of potential of A. terreus strains we also examined the feasibility of SSF for lovastatin production. SSF on natural solid substrates is being considered as the most common and the best option for production of microbial metabolites with use of cheap raw materials. Lovastatin production in SSF on natural solid substrates has been studied by Valera et al. with Aspergillus flaviceps (Valera et al., 2005), Wei et al. with Aspergillus terreus (Wei et al., 2007), Xu et al. with Monascus ruber (Xu et al., 2005), who have shown lovastatin yields of 4-6 mg/g, 2,9 mg/g, 16,78 mg/g, respectively. Szakacs et al. used solid substrates such as wheat bran and sweet sorghum pulp and reported that SSF is superior than SmF for lovastatin production (Szakacs et al., 1998).

In our experiments we used rice bran, wheat bran, oat bran, maize bran and mix of wheat and peanut bran as solid substrates grounded to the size of 20 mesh as used by Wei et al. (2007). 


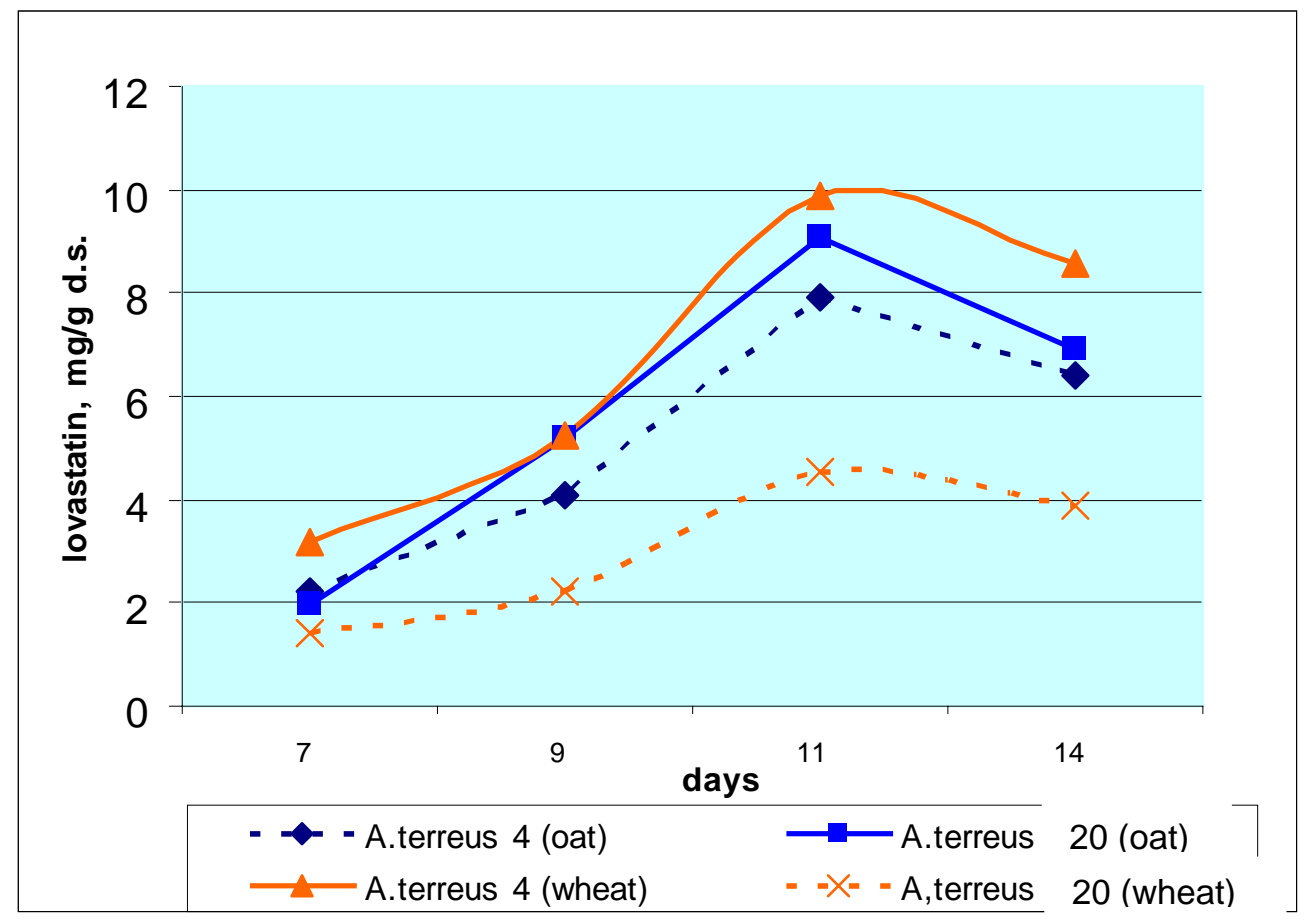

Figure1. Time course of lovastatin production in solid-state fermentation of Aspergillus terreus with oat and wheat bran

As shown in Figure1, biosynthesis of lovastatin in both strains reaches its maximum by the $11^{\text {th }}$ day of growth on oat and wheat bran. The same dynamic of lovastatin accumulation we have observed at SSF on all used substrates.

Table 2. Effect of different solid substrates on lovastatin yield by Aspergillus terreus strains

\begin{tabular}{|c|c|c|}
\hline \multirow{2}{*}{ Strains } & Solid substrate & $\begin{array}{c}\text { Lovastatin titer } \\
(\mathrm{mg} / \mathrm{g})\end{array}$ \\
\hline \multirow{3}{*}{ A.terreus 20} & Rice & 2,67 \\
\cline { 2 - 3 } & Wheat & 5,54 \\
\cline { 2 - 3 } & Oat & 9,56 \\
\cline { 2 - 3 } & Wheat + peanut $(1: 1)$ & 0,4 \\
\cline { 2 - 3 } & Maize & 3,2 \\
\hline \multirow{5}{*}{ A.terreus 4 } & Rice & 4,2 \\
\cline { 2 - 3 } & Wheat & 9,7 \\
\cline { 2 - 3 } & Oat & 8,4 \\
\cline { 2 - 3 } & Wheat + peanut $(1: 1)$ & 4,8 \\
\cline { 2 - 3 } & Maize & 4,4 \\
\hline
\end{tabular}

The summary results presented in Table 2 show that when using oat and wheat brans as substrates both $A$. terreus strains had nearly similar productivity which was higher than for the rest of the substrates. The yields of lovastatin in extracts of $A$. terreus 4 and A. terreus 20 after SSF are comparable with ones previously reported for Monascus ruber (Xu et al., 2005), A. flavipes BICC 5174 (Valera et al., 2005), and was significantly higher than for A. terreus 20524 (Wei et al., 2007; Jaivel et al., 2010).

Comparison of data for submerged and solid-state fermentation methods for lovastatin production by $A$. terreus 4 and by $A$. terreus 20 have demonstated a clear advantage for SSF with productivity increase on solid substrates by more than 30 times ( 9.7 и $9.56 \mathrm{mg} / \mathrm{g}$ against 0.276 and $0.236 \mathrm{mg} / \mathrm{ml}$, respectively). 


\section{Conclusions}

The ability of two indigenous strains of A. terreus to produce lovastatin in SmF and SSF have been studied. In SmF, lovastatin yield was elevated on lactose based media and reached its maximum - $276 \mathrm{mg} / \mathrm{l}$ and $236 \mathrm{mg} / \mathrm{l}$ by A. terreus 4 and $A$. terreus 20, respectively. In SSF with various substrates used - wheat bran, oat bran, maize bran, rice bran and mixed wheat and peanut bran - the preferred substrate was wheat and oat bran and maximum titers of lovastatin were 9.7 and $9.56 \mathrm{mg} / \mathrm{g}$, for $A$. terreus 4 and A. terreus 20, respectively.

\section{References}

Alberts A.W., Chen J., Kuron G., Hunt V., Huff J., Hoffman C., Rothrock J., Lopez M., Joshua H., Harris E., Patchett A., Monaghan R., Currie S., Stapley E., Albers-Schonberg G., Hensens O., Hirshfield J., Hoogsteen K., Liesch J., Springer J. 1980. Mevinolin: a highly potent competitive inhibitor of hydroxymethylglutaryl-coenzyme A reductase and a cholesterol- lowering agent. Proceedings of the National Academy of Sciences of the United States of America, Vol. 77, pp. 3957-3961.

Barrios-Gonzales J., Miranda R.U. 2010. Biotechnological production and applications of statins. Applied Microbiology and Biotechnology, Vol. 85, pp. 869-883.

Bizukojc M. and Ledakowicz S. 2009. Physiological, morphological and kinetic aspects of lovastatin biosynthesis by Aspergillus terreus. Journal of Biotechnology, Vol. 4, pp. 647-664.

Casas Lopez J. L., Sanchez Perez J.A., Fernandez Sevilla J.M., Acien Fernandez F. G. et al. 2003. Production of lovastatin by Aspergillus terreus: effects of the $\mathrm{C}: \mathrm{N}$ ratio and the principal nutrients on growth and metabolite production. Enzyme Microbial Technol., Vol. 33, pp. 270-277.

Hajjaj H., Niederberger P., Duboc P. 2001. Lovastatin biosynthesis by Aspergillus terreus in a chemically defined medium. Applied and Environmental Microbiology, Vol. 67, pp. 2596-2602.

Holker U., Hofer M., Lenz J. 2004. Biotechnological advantages of laboratory-scale solid-state fermentation with fungi. Applied Microbiology and Biotechnology, Vol. 64, pp. 175-186.

Jaivel N., Marimuthu P. 2010. Optimization of lovastatin production in solid state fermentation by Aspergillus terreus. International Journal of Engineering, Science and Technology, Vol. 2, pp. 2730-2733.

Kumar M.S., Jana S.K., Senthil V., Shashanka S., Kumar S.V., Sadhukhan A.K. 2000. Repeated fed-batch process for improving lovastatin production. Process Biochemistry, Vol. 36, pp. 363-368.

Lai L.-S. T., Hung C.-S. H., Lo C.-C. 2007. Effects of lactose and glucose on production of itaconic acid and lovastatin by Aspergillus terreus ATCC20542. Journal of Bioscience and Bioengineering, Vol. 104, pp. 9-13.

Lai L.-S. T., Tsai T.-H., Wang T. C., Cheng T.-Y. 2005. The influence of culturing environments on lovastatin production by Aspergillus terreus in submerged cultures. Enzyme and Microbial Technology, Vol. 36, pp. 737-748.

Manzoni M., Rollini M., Bergomi S., Cavazzoni V. 1998. Production and purification of statins from Aspergillus terreus strains. Biotechnology Techniques, Vol. 12, pp. 529-532.

Manzoni M., Rollini M. 2002. Biosynthesis and biotechnological production of statins by filamentous fungi and application of these cholesterol-lowering drugs. Applied Microbiology and Biotechnology, Vol. 5, pp. 555-564.

Monaghan R., Alberts A., Hoffman C., Albers-Schonberg G. 1981. Hypocholesterolemic fermentation products and process of preparation. U.S. Patent 4294926.

Morovjan G., Szakacs G. and Fekete J. 1997. Monitoring of selected metabolites and biotransformation products from fermentation broths by high-performance liquid chromatography. Journal of Chromatography. A, Vol. 763, pp. 165-172.

Szakacs G., Morovjan G., Tengerdy R. P. 1998. Production of lovastatin by a wild strain of Aspergillus terreus. Biotechnology Letters, Vol. 20, pp. 411-415.

Valera H.R., Gomes J., Lakshmi S., Gururaja R., Suryanarayan S., Kumar D. 2005. Lovastatin production by solid state fermentation using Aspergillus flavipes. Enzyme and Microbial Technology, Vol. 37, pp. 521-526.

Wei P., Xu Z., Cen P. 2007. Lovastatin production by Aspergillus terreus in solid state fermentation. Journal of Zhejiang University-SCIENCE A, Vol. 8, pp. 1521-1526.

Xu B.J., Wang Q.J., Jia X.Q., Sung C.K. 2005. Enhanced lovastatin production by solid state fermentation of Monascus rubber. Biotechnology and Bioprocess Engineering, Vol. 10, pp. 78-84.

\section{Biographical notes}

T.G. Gulyamova is a Professor in the Department of Biochemistry and Biotechnology of Physiologically Active Compounds, Institute of Microbiology, Uzbekistan. She has more than 30 years of experience in research. Her research interests include biodiversity and biochemistry of biotechnologically important fungi, including endophytes from medicinal plants, regulation of microbial synthesis of physiologically active secondary metabolites. She has published more than forty papers in referred international journals. She has also presented more than one hundred research articles in national and international conferences. She is currently dealing with few projects sponsored by government of Uzbekistan and USA.

D.M. Ruzieva received Ph.D. from the Institute of Microbiology, Uzbekistan Academy of Sciences in 1993. She is Senior Research Fellow in the Department of Biochemistry and Biotechnology of Physiologically Active Compounds, Institute of Microbiology, Uzbekistan. Her current area of research includes biosynthesis 
of secondary metabolites in fungi. She has presented about fifty research articles in national and international conferences. Currently she is dealing with few projects sponsored by governments of Uzbekistan and USA.

S.M. Nasmetova received Ph.D. from the Institute of Microbiology, Uzbekistan Academy of Sciences in 2008. She is Senior Research Fellow in the Department of Biochemistry and Biotechnology of Physiologically Active Compounds, Institute of Microbiology, Uzbekistan. Her current area of research includes regulation of biosynthesis of statins by fungi, submerged and solid state fermentation processes, optimization technology. She is dealing with two projects sponsored by government of Uzbekistan.

R.S. Sattarova received Ph.D. from the Institute of Microbiology, Uzbekistan Academy of Sciences in 1993. She is Senior Research Fellow in the Department of Biochemistry and Biotechnology of Physiologically Active Compounds, Institute of Microbiology. She has received various fellowships and awards of International Organizations like DAAD, Germany; ITCILO, Italy; Royal Society, UK ; etc. Her research area includes search and study of bioactive metabolites of microorganisms with medicinal and agricultural potential. She coordinated over 20 donor funded R\&D projects supported by USA and EU in the framework of program 'Science and Technology Center in Ukraine'. She is currently dealing with few projects sponsored by governments of Uzbekistan and Korea.

K.V. Lobanova received Ph.D. from the Institute of Microbiology, Uzbekistan Academy of Sciences in 2010. She is Senior Research Fellow in the Department of Biochemistry and Biotechnology of Physiologically Active Compounds, Institute of Microbiology, Uzbekistan. Her current area of research is qualitative analysis of nature and functions of fungal secondary metabolites. She is dealing with one project sponsored by government of Uzbekistan.

L.A. Abdulmyanova received Ph.D. from the Institute of Microbiology, Uzbekistan Academy of Sciences in 2008. She is Senior Research Fellow in the Department of Biochemistry and Biotechnology of Physiologically Active Compounds, Institute of Microbiology, Uzbekistan. Her current area of research includes biodiversity of fungi, cultural and physiological peculiarities of production of secondary metabolites. She is dealing with two projects sponsored by government of Uzbekistan.

G.A.Rasulova is Technical Assistant in the Department of Biochemistry and Biotechnology of Physiologically Active Compounds, Institute of Microbiology, Uzbekistan. She is dealing with two projects sponsored by government of Uzbekistan.

Received February 2013

Accepted March 2013

Final acceptance in revised form March 2013 